\title{
PENINGKATAN KETERAMPILAN BERBICARA MENGGUNAKAN METODE KOOPERATIF TIPE JIGSAW PADA MAHASISWA PBSI TINGKAT I-B IKIP PGRI BOJONEGORO TAHUN AKADEMIK 2018/2019
}

\author{
Agus Darmuki ${ }^{1}$, Ahmad Hariyadi ${ }^{2}$ \\ agus_darmuki@yahoo.co.id ${ }^{1}$, ahmadhariyadi31@yahoo.co.id ${ }^{2}$ \\ Prodi Pendidikan Bahasa dan Sastra Indonesia ${ }^{1}$, Prodi Pendidikan Kewarganegaraan ${ }^{2}$ \\ IKIP PGRI Bojonegoro, Indonesia
}

\begin{abstract}
Abstrak
Tujuan penelitian ini untuk meningkatkan: (1) kualitas proses (keaktifan) pembelajaran berbicara dengan menggunakan metode kooperatif tipe Jigsaw pada mahasiswa prodi PBSI tingkat I-B IKIP PGRI Bojonegoro dan (2) hasil pembelajaran keterampilan berbicara dengan menerapkan metode kooperatif tipe Jigsaw pada mahasiswa prodi PBSI tingkat I-B IKIP PGRI Bojonegoro. Penelitian ini merupakan penelitian tindakan kelas. Penelitian ini subjeknya adalah mahasiswa tingkat I-B berjumlah 40 mahasiswa yang terdiri atas 30 mahasiswa perempuan dan 10 mahasiswa laki-laki dan satu orang dosen pengampu matakuliah keterampilan berbicara. Objek penelitian ini adalah kegiatan pembelajaran berbicara. Teknik pengumpulan data yang digunakan adalah observasi, wawancara mendalam, dan analisis dokumen. Teknik validitas data menggunakan teknik triangulasi sumber data dan triangulasi metode. Teknik analisis data pada penelitian ini menggunakan teknik analisis deskripsi komparatif dan analisis interaktif. Penelitian tindakan kelas ini dilakukan dalam dua siklus yang meliputi empat tahapan, yaitu: perencanaan, pelaksanaan, observasi, dan refleksi. Hasil penelitian ini menunjukkan adanya peningkatan hasil pembelajaran berbicara, ditandai dengan meningkatnya jumlah mahasiswa yang mencapai batas ketuntasan, yaitu pada siklus I ada 32 mahasiswa ( $80 \%$ ), pada siklus II ada 38 mahasiswa (95\%), dan pada siklus III ada 40 mahasiswa (100\%). Simpulan penelitian ini menunjukkan bahwa penerapan metode kooperatif tipe Jigsaw dapat meningkatkan keaktifan mahasiswa, proses dan hasil pembelajaran keterampilan berbicara mahasiswa.
\end{abstract}

Kata kunci: Peningkatan, berbicara, Jigsaw.

\begin{abstract}
The purpose of this study is to improve: (1) the quality of the process (activeness) of learning by using the Jigsaw cooperative method on PBSI I-B level students at IKIP PGRI Bojonegoro and (2) speaking skills learning outcomes by applying the Jigsaw cooperative method to PBSI level study students IB IKIP PGRI Bojonegoro. This research is a classroom action research. This research subject is 40 students of I-B level consisting of 30 female students and 10 male students and one speaking lecturer. The object of this research is learning speaking activities. Data collection techniques used were observation, in-depth interviews, and document analysis. The data validity technique uses data source triangulation techniques and method triangulation. The data analysis technique in this study uses comparative description analysis techniques and interactive analysis. This classroom action research was conducted in two cycles which included four stages, namely: planning, implementation, observation, and reflection. The results of this study indicate an increase in speaking learning outcomes, marked by an increase in the number of students who reached the completeness limit, namely in the first cycle there were 32 students $(80 \%)$, in the second cycle there were 38 students (95\%), and in the third cycle there were 40 students $(100 \%)$. The conclusions of this study indicate that the application of the Jigsaw type cooperative method can increase student activity, process and learning outcomes of student speaking skills.
\end{abstract}

Keynotes: upgrading, speak, jigsaw.

\section{PENDAHULUAN}

Kegiatan berbicara sebagai bagian dari keterampilan berbahasa sangat penting, baik bagi pengajaran maupun di dalam kehidupan seharihari (Darmuki dkk., 2018). Oleh karena itu, penguasaan keterampilan

256 | Jurnal Kredo Vol. 2 No. 2 April 2019 berbicara harus dimiliki oleh setiap orang termasuk mahasiswa. Berkomunikasi secara lisan dengan teman, mengikuti kuliah, diskusi, seminar, presentasi, MC dan debat menuntut adanya kemahiran seseorang dalam berbicara. Sehubungan dengan pernyataan di 
atas, maka dalam kegiatan belajar mengajar di Program Studi Pendidikan Bahasa dan Sastra Indonesia, keterampilan berbicara menjadi salah satu bagian yang wajib diajarkan kepada mahasiswa dan harus dikuasai oleh semua mahasiswa tersebut.

Pada

kenyataannya, berdasarkan hasil survei awal yang dilakukan oleh peneliti, diketahui bahwa kualitas hasil pembelajaran keterampilan berbicara, khususnya presentasi dan diskusi pada mahasiswa tingkat I-B Program Studi Pendidikan Bahasa dan Sastra Indonesia IKIP PGRI Bojonegoro, masih tergolong rendah. Hal ini dapat dilihat dari nilai rata-rata kelas I-B, dalam tes mata kuliah berbicara semester I (gasal) tahun akademik 2018/2019 dan hasil pengamatan langsung, yang hanya mencapai nilai 6,50 (enam koma lima puluh). Padahal Kriteria Ketuntasan Minimal (KKM) untuk mata kuliah berbicara di kelas I-B Program Studi Pendidikan Bahasa dan Sastra Indonesia IKIP PGRI Bojonegoro adalah 7,00 (tujuh koma nol nol).

Hasil wawancara awal sebelum tindakan dengan dosen pengajarnya, dikatakan bahwa "rendahnya keterampilan berbicara untuk mahasiswa disebabkan oleh beberapa faktor, yaitu: (1) mahasiswa kurang berminat pada pembelajaran berbicara. Sebagian besar mahasiswa menyatakan bahwa pembelajaran berbicara merupakan materi yang tidak menyenangkan. Menurut mahasiswa cara mengajar dosen dalam pembelajaran berbicara kurang menarik; (2) sebagian besar mahasiswa mengalami kesulitan dan takut untuk mengungkapkan pendapat/gagasan dengan bahasa yang baik dan benar ketika dosen memberi pertanyaan atau tampil berbicara di depan kelas. Dari dosen (1) mengalami kesulitan untuk membangkitkan minat mahasiswa dalam pembelajaran keterampilan berbicara; (2) dosen mengalami kesulitan untuk menemukan alternatif metode pembelajaran yang tepat dalam mengajarkan keterampilan berbicara kepada mahasiswa.

Berbicara merupakan suatu kompetensi yang dapat dicapai melalui belajar dan berlatih (Kayi, 2006; Bahrani \& Soltani, 2008; Lourdunathan \& Menon, 2011; Thuy, 2012; Darmuki dkk., 2017). Kompetensi yang diinginkan akan dapat dicapai apabila mahasiswa dilatih berbicara dan diberi kesempatan yang sebanyakbanyaknya untuk tampil berbicara (Pan, 2010). Oleh karena itu, pembelajaran berbicara harus dilaksanakan dengan menciptakan situasi belajar yang memungkinkan mahasiswa dapat mengembangkan keterampilan berbicara dan memberikan kesempatan kepada mahasiswa berlatih berbicara di kelompok kecil sebelum tampil di depan kelas. Tanpa keberanian atau keberanian yang setengah-setengah akan mengakibatkan kacaunya kegiatan komunikasi lisan atau berbicara. 
Merefleksikan fenomena di atas, maka metode kooperatif tipe jigsaw perlu diterapkan sebagai alternatif dalam menyelesaikan masalah dengan mengantisipasi kegiatan pembelajaran keterampilan berbicara berupa Penelitian Tindakan Kelas (PTK). Metode kooperatif tipe Jigsaw tersebut dipilih karena merupakan salah satu unit dari pendekatan Cooperatif Learning, memiliki sifat belajar yang tidak sama dengan cara belajar bersama seperti biasa. Juga karena para dosen pada umumnya menggunakan metode konvensional, sehingga menimbulkan persaingan terjadi di dalam kelas yang berdampak negatif bagi mahasiswa.

Dalam pembelajaran pada umumnya, dosen membentuk kelompok belajar lalu memberikan tugas tanpa rancangan tertentu yang dapat membuat setiap mahasiswa menjadi aktif. Akibatnya, ada mahasiswa yang aktif bekerja, tetapi ada juga yang pasif, ataupun bahkan ada yang ramai sendiri. Sedangkan dalam pembelajaran dengan pendekatan Cooperatif Learning, setiap mahasiswa dituntut untuk aktif bekerja dalam kelompok melalui rancangan-rancangan tertentu yang sudah dipersiapkan sebelumnya oleh dosen, sehingga seluruh mahasiswa harus aktif bekerja dan belajar. Penerapan metode Jigsaw ini, bagi mahasiswa dapat termotivasi untuk mengungkapkan ide atau gagasan secara lisan di dalam wadah kelompoknya. Mahasiswa memiliki tempat dan kesempatan untuk curah pendapat dengan teman-teman mereka sebaya. Selain itu, tujuan Cooperatif Learning adalah menciptakan sebuah situasi, agar bagaimana cara anggota kelompok bisa meraih tujuan pribadi mereka, dan melalui kelompok bisa sukses untuk melakukan usaha belajar secara maksimal (Gilles \& Michael, 2010).

Berdasarkan uraian permasalahan mengenai pembelajaran keterampilan berbicara di atas, peneliti mengatasi masalah pembelajaran keterampilan berbicara tersebut dengan menerapkan model pembelajaran kooperatif tipe jigsaw. Selanjutnya peneliti menerapkan penggunaan model pembelajaran kooperatif tipe jigsaw tersebut dalam upaya meningkatkan keterampilan berbicara mahasiswa Kelas IB Program Studi Pendidikan Bahasa dan Sastra Indonesia IKIP PGRI Bojonegoro 2018 / 2019.

\section{KAJIAN TEORI}

Berbicara merupakan komunikasi verbal secara lisan dan langsung antara penutur dan mitra tutur yang bisa juga dengan menggunakan media komunikasi audio atau audiovisual agar gagasan itu dapat dipahami (Eric, 2008: 3). Berbicara tidak hanya sekedar menyampaikan gagasan lisan, tetapi yang lebih penting adalah bagaimana gagasan itu dapat dipahami oleh pendengar. Sebelum melakukan aktivitas berbicara, ia melakukan kegiatan menyimak terlebih dahulu. 
Hasil penyimakan merupakan dasar keterampilan berbicara, dari proses menyimak inilah seseorang mulai belajar berbicara. Kemampuan berbicara seseorang akan baik jika aktivitas menyimaknya juga dilalui dengan baik pula (Nurgiyantoro, 2001: 276). Seseorang dikatakan terampil berbicara jika setidaknya memiliki empat kompetensi yakni gramatikal, sosiolinguistik, analisis wacana dan strategi (Liao, 2009: 645). Oleh karena itu, faktor penguasaan bahasa tidak dapat diabaikan begitu saja.

Pendapat Hughes (2003: 113) sebagai berikut: "The objective of teaching spoken language is the development of the ability to interact successfully in that language". Tujuan pengajaran berbicara adalah untuk mengembangkan kemampuan berinteraksi atau berkomunikasi secara berhasil dalam bahasa tersebut. Keberhasilan penguasaan keterampilan bebicara seseorang ditunjang oleh faktor kebahasaan dan nonkebahasaan (Bygate, 2000: 1014). Faktor kebahasaan berkaitan dengan penguasaan unsur-unsur linguistik dan kaidah tata bahasa lainnya, sedangkan nonkebahasaan berhubungan dengan penguasaan diri, sikap, dan hubungan sosial pembicara. Faktor-faktor kebahasaan sebagai penunjang keefektifan berbicara, antara lain (Thornbury, 2001: 52), (1) ketepatan ucapan/ vokal; (2) pengucapan konsonan; (3) penempatan tekanan (4) penempatan persendian; (5) penggunaan nada/ irama; (6) pilihan kata (diksi); (7) ketepatan ungkapan; (8) tata bentukan kata; (9) pola struktur kalimat. Sedangkan faktor nonkebahasaan yang mendukung keterampilan berbicara (Hughes, 2003: 43), antara lain: (1) Sikap yang wajar, tenang, dan tidak kaku; (2) Pandangan harus diarahkan kepada lawan bicara; (3) Kesediaan menghargai pendapat orang lain; (4) kinesik dan mimik yang tepat; (5) Kenyaringan suara; (6) Kelancaran, relevansi/penalaran; (7) Penguasaan topik; (8) kejelasan isi.

Cooperatif Learning adalah suatu model pembelajaran dimana siswa belajar dan bekerja dalam kelompok-kelompok kecil secara kolaboratif yang anggotanya terdiri dari 4-5 orang dengan struktur kelompoknya yang bersifat heterogen (Slavin, 2010: 240). Metode Jigsaw merupakan salah satu bentuk belajar kooperatif yang mensyaratkan adanya bahan ajar tertulis yang dapat dipelajari mahasiswa. Model kooperatif jenis jigsaw pertama kali diperkenalkan oleh Aronson dkk., Dalam bukunya The Jigsaw Classroom (1978). Moskowits dkk., dalam Journal Contemporary Educational Psychology (1985, 10, 104-112) menulis topik ini dengan judul Evaluation of Jigsaw Cooperatif Technique. Selanjutnya jigsaw dikembangkan oleh Mattingly dan Vansickle dalam tulisannya pada Journal Social Education (1991, 55, (6, 392-395) dengan topik Cooperatif Learning of Achievment in Social Studies: Jigsaw II. Dalam Jigsaw 
sangat dipentingkan kemampuan individual mahasiswa untuk menjadi peer-tutor bagi temannya sekelompok (Paulina Pannen, 2005: 71). Melalui metode Jigsaw kelas dibagi atas beberapa kelompok, tiap kelompok anggotanya 4-5 orang (Trianto, 2007: 56). Mahasiswa bekerja dengan sesama mahasiswa dalam suasana gotong royong dan mempunyai banyak kesempatan untuk mengolah informasi dan meningkatkan keterampilan berkomunikasi (Lie, 2008: 69).

Penilaian dalam berbicara menyangkut dua aspek yaitu aspek keterampilan dan aspek kemampuan kognitif. Aspek keterampilan dapat dilihat dari segi kelancaran dan kewajaran gerakan. Adapun aspek kognitif mencakup: (1) keakuratan informasi; (2) hubungan antarinformasi; (3) ketepatan struktur dan kosakata; (4) kelancaran; (5) kewajaran urutan wacana; (6) gaya pengucapan (Nurgiantoro, 2001: 278-292). Rubrik penskoran bahasa lisan menggunakan model O'mally dan Pierce (1996: 67) yang sejalan dengan konsep Bailey (2005: 42) penilaian kecakapan berbicara meliputi unsur-unsur kebahasaan: pemahaman, pelafalan, kosakata, tata bahasa dan kefasihan. Berdasarkan beberapa pendapat di atas dapat disimpulkan bahwa penelitian ini dilakukan penilaian autentik dengan mengamati dan menilai performansi mahasiswa berbicara di depan kelas serta tes untuk mengetahui pemahaman mahasiswa.

260 | Jurnal Kredo Vol. 2 No. 2 April 2019

\section{METODE PENELITIAN}

Jenis penelitian ini adalah penelitian tindakan kelas. Penelitian ini dilaksanakan di Program Studi Pendidikan Bahasa dan Sastra Indonesia kelas I-B IKIP PGRI Bojonegoro Tahun Akademik 2018/2019 semester I (gasal) dengan tiga siklus, setiap siklus terdiri dari empat aspek. Kemmis (2009) menyebutkan empat aspek dalam penelitian tindakan kelas, yaitu: perencanaan tidakan (planning), pelaksanaan tindakan (acting), pengamatan (observasing) dan refleksi (reflecting). Penelitian ini dengan subjek mahasiswa tingkat I-B yang berjumlah 40 orang dengan rincian terdiri dari 30 mahasiswa perempuan dan 10 mahasiswa lakilaki serta satu orang dosen pengampu matakuliah keterampilan berbicara. Sumber data penelitian ini adalah kegiatan pembelajaran berbicara di Prodi PBSI kelas I-B IKIP PGRI Bojonegoro. Teknik pengumpulan data menggunakan wawancara, dokumentasi, observasi dan tes. Teknik validitas data menggunakan teknik triangulasi sumber data dan triangulasi metode. Teknik analisis data yang digunakan adalah teknik analisis deskripsi komparatif dan analisis interaktif.

\section{HASIL DAN PEMBAHASAN}

Hasil tes keterampilan berbicara menggunakan metode Jigsaw pada tindakan siklus I menunjukkan mahasiswa yang sudah mencapai batas Kriteria Ketuntasan 
Minimal (KKM) yang ditetapkan 70 didapat 32 mahasiswa (80\%) sudah mampu berbicara dengan cukup baik, sedangkan 8 mahasiswa (20\%) masih perlu perbaikan. Hal ini dapat dibandingkan hasil prestasi mahasiswa dari sebelum tindakan siklus I yang telah mencapai ketuntasan belajar dengan melampaui KKM hanya 18 mahasiswa (45\%) kemudian meningkat menjadi 32 mahasiswa (80\%) setelah adanya tindakan siklus I, terjadi kenaikan 20\%. Hasil tindakan pembelajaran pada siklus I dapat dikatakan berjalan dengan cukup baik, walaupun dari hasil observasi terhadap kegiatan proses belajar mengajar masih banyak kelemahan, mahasiswa masih pasif, belum banyak yang aktif serta dosen belum menerapkan metode Jigsaw secara maksimal, dosen belum mampu mengelola kelas secara maksimal. Temuan tersebut akan direfleksikan pada tindakan siklus II.

$$
\text { Hasil tes keterampilan }
$$
berbicara menggunakan metode Jigsaw pada tindakan siklus II menunjukkan mahasiswa yang sudah mencapai batas Kriteria Ketuntasan Minimal (KKM) yang ditetapkan 70 di dapat 38 mahasiswa (95\%), sedangkan mahasiswa yang lain belum mencapai batas ketuntasan minimal sebanyak 2 mahasiswa (5\%) dan masih memerlukan perbaikan. Kelemahan yang dimiliki dosen pada tindakan siklus I sudah mampu teratasi dengan baik pada tindakan siklus II. Kemudian pada pelaksanaan tindakan siklus II, dosen sudah mampu mengelola kelas dengan baik sehingga relatif tidak ditemukan kelemahan. Selanjutnya kelemahan dari mahasiswa kemampuan dan kecepatan berbicara mahasiswa masih rendah, masih banyak mahasiswa yang tampil berbicara dengan suara pelan dan lemah.

Hasil tes keterampilan berbicara menggunakan metode Jigsaw pada tindakan siklus III menunjukkan mahasiswa $100 \%$ tuntas, hal ini bentuk usaha dosen memberikan penghargaan kepada mahasiswa dalam bentuk pujian dan hadiah-hadiah. Berikut hasil tindakan siklus I, II, dan III yang dapat dilihat pada tabel berikut ini.

Tabel 1. Hasil Pembelajaran Berbicara Mahasiswa

\begin{tabular}{lllllll}
\hline \multirow{2}{*}{ No } & \multirow{2}{*}{ Nilai } & \multicolumn{2}{l}{ Jumlah Mahasiswa } & & Keterangan \\
\cline { 3 - 7 } & & Pratindakan & Siklus 1 & Siklus 2 & Siklus 3 & \\
\hline 1 & $\geq 69$ & 22 & 8 & 2 & 0 & Tidak Tuntas \\
\hline 2 & $70-80$ & 10 & 10 & 8 & 4 & Tuntas \\
\hline 3 & $81-90$ & 7 & 12 & 12 & 16 & Tuntas \\
\hline 4 & $91-100$ & 1 & 10 & 18 & 20 & Tuntas \\
\hline
\end{tabular}


Berdasarkan tabel di atas, tindakan yang dilakukan dosen dengan menerapkan pembelajaran kooperatif tipe Jigsaw berhasil dan mampu meningkatkan kemampuan mahasiswa dalam berbicara. Selain itu, kemampuan dosen dalam hal penguasaan kelas saat pembelajaran mata kuliah berbicara meningkat dan dalam melaksanakan pembelajaran yang efektif dan menarik di kelas. Keberhasilan penggunaan metode kooperatif tipe Jigsaw dalam meningkatkan keaktifan mahasiswa selama proses pembelajaran dan kemampuan mahasiswa dalam berbicara dapat dilihat dari indikatorindikator sebagai berikut.

Tabel 2. Hasil Observasi Keaktifan Mahasiswa dalam Pembelajaran

\begin{tabular}{|c|c|c|c|c|c|}
\hline \multirow{2}{*}{ No } & \multirow{2}{*}{ Indikator } & \multicolumn{4}{|c|}{ Presentasi yang Dicapai } \\
\hline & & Prasiklus & Siklus 1 & Siklus 2 & Siklus 3 \\
\hline 1 & $\begin{array}{l}\text { Keaktifan mahasiswa } \\
\text { apersepsi }\end{array}$ & $20 \%$ & $70 \%$ & $78 \%$ & $83 \%$ \\
\hline 2 & $\begin{array}{lll}\text { Keaktifan mahasiswa } & \text { dalam } \\
\text { memperhatikan penjelasan } & \text { materi } \\
\text { dosen } & & \end{array}$ & $37 \%$ & $67 \%$ & $93 \%$ & $95 \%$ \\
\hline 3 & $\begin{array}{lr}\text { Keberanian mahasiswa } & \text { dalam } \\
\text { mengungkapkan } & \text { pendapat } \\
\text { (berbicara) } & \end{array}$ & $50 \%$ & $80 \%$ & $81 \%$ & $90 \%$ \\
\hline 4 & $\begin{array}{l}\text { Keaktifan mahasiswa } \\
\text { diskusi }\end{array}$ & $46 \%$ & $66 \%$ & $78 \%$ & $88 \%$ \\
\hline 5 & Ketuntasan hasil belajar berbicara & $45 \%$ & $80 \%$ & $95 \%$ & $100 \%$ \\
\hline
\end{tabular}

Berdasarkan tabel di atas penerapan metode pembelajaran kooperatif tipe Jigsaw juga mampu meningkatkan keaktifan, kerjasama, dan hasil belajar mahasiswa dalam proses pembelajaran keterampilan berbicara. Hal ini dikarenakan dalam metode kooperatif tipe Jigsaw semua mahasiswa mempunyai peran untuk berbicara secara bergantian. Pelaksanaan pembelajaran saat diskusi, mahasiswa dituntut menguasai materi, aktif dalam diskusi, dan mampu berbicara menyampaikan materi kepada teman satu kelompok atau kelompok lainnya. Penggunaan metode kooperatif tipe Jigsaw dapat meningkatkan keaktifan mahasiswa selama proses pembelajaran sehingga hasil praktik berbicara mereka juga meningkat. Selain itu, penggunaan metode kooperatif tipe Jigsaw memberikan dampak kepada mahasiswa menjadi lebih antusias dan berminat dalam mengikuti pembelajaran berbicara. Bentuk antusiasme dan minat tersebut terlihat dari banyaknya mahasiswa yang aktif memberikan respon terhadap apersepsi yang diberikan dosen, memperhatikan penjelasan materi yang diberikan dosen, dan aktif dalam berdiskusi kelompok.

Peningkatan kualitas hasil pembelajaran keterampilan berbicara dengan metode Jigsaw berdasarkan hasil pelaksanaan tindakan siklus I, 
II, III dapat dikatakan terjadi peningkatan kualitas pembelajaran keterampilan berbicara. Berdasarkan tindakan-tindakan siklus I, II, III tersebut dosen telah berhasil melaksanakan pembelajaran keterampilan berbicara menggunakan metode Jigsaw mampu mengembangkan secara optimal keterampilan mahasiswa dan meningkatkan kualitas proses, keaktifan dan hasil pembelajaran.

$$
\text { Berdasarkan }
$$

hasil

pengamatan peneliti (tabel 2), maka dapat dikatakan bahwa tindakan dosen cukup berhasil dalam meningkatkan keaktifan mahasiswa. Penggunaan metode kooperatif tipe Jigsaw memiliki peranan penting dalam meningkatkan keaktifan, tanggungjawab dan mahasiswa menjadi lebih fokus dalam proses pembelajaran telah terbukti. Sesuai pendapat Slavin (2010: 256) pembelajaran Jigsaw sangat baik untuk menambahkan tanggung jawab individual kepada diskusi kelompok, karena sebelumnya tidak diberi tahu siapa akan mewakili kelompok (ahli) dalam mengemukakan jawaban sehingga setiap mahasiswa menjadi lebih fokus dan aktif. Peningkatan segi keaktifan mahasiswa ini dapat dilihat dari indikator berikut: (a) Meningkatnya respon mahasiswa selama apersepsi; (b) Keaktifan mahasiswa dalam pembelajaran merupakan hal pokok dalam proses pembelajaran.

Apersepsi menjadi langkah awal dalam pembelajaran yang harus dilakukan dosen untuk mengaktifkan mahasiswa. Dosen melakukan apersepsi melalui skemata terkait dengan topik penting sebelum penyampaian materi pelajaran. Dosen pada apersepsi ini selalu mengawali dengan pertanyaan sesuai topik pelajaran yang akan dipelajari saat itu. Mahasiswa dalam memberikan respon terhadap apersepsi yang dilakukan dosen selalu mengalami peningkatan dari siklus I ke siklus II dan siklus III.

Fokus dan perhatian
mahasiswa
pembelajaran merupakan hal yang sangat penting. Dosen untuk menumbuhkan perhatian tersebut, harus memotivasi mahasiswa dengan menerapkan cara-cara baru yang digunakan dalam proses pembelajaran. Seperti yang disampaikan Darmuki dkk, (2017: 79) Dosen dalam pembelajaran berbicara dituntut agar menumbuhkan perhatian terhadap pembelajaran sehingga mereka termotivasi untuk mengikuti pembelajaran berbicara dengan cara yang menyenangkan. Dalam penelitian ini, dosen menggunakan metode kooperatif tipe Jigsaw hasilnya mahasiswa lebih fokus belajarnya. Perhatian mahasiswa dalam proses pembelajaran keterampilan berbicara meningkat setelah tindakan tersebut dilakukan. Meningkatnya perhatian mahasiswa terhadap pembelajaran berbicara menggunakan kooperatif tipe Jigsaw juga telah membuktikan bahwa telah tercipta suasana pembelajaran yang menyenangkan bagi mahasiswa 
(Kagan, 2009: 63; Attle \& Baker, 2007). Dalam hal ini, mahasiswa merasa mendapatkan suasana yang baik dalam penggunaan metode pembelajaran yang baru dari dosen.

Penggunaan

metode

kooperatif dapat meningkatkan keaktifan mahasiswa dalam kegiatan berdiskusi. Diskusi dalam pembelajaran berbicara yang dilakukan mahasiswa bertujuan agar mahasiswa bekerja sama dengan temannya. Melalui kerja sama, mahasiswa diharapkan lebih memiliki rasa tanggung jawab terhadap pembelajarannya sendiri dan juga orang lain. Begitu pula Kagan (2009) menyatakan bahwa metode pembelajaran kooperatif tipe Jigsaw bertumpu pada kerja kelompok kecil, berlawanan dengan pembelajaran klasikal (satu kelas penuh). Dengan demikian mahasiswa dituntut bekerja sama dalam diskusi dan saling membantu satu sama lain.

Keberanian mahasiswa menyampaikan ide dan informasi materi saat pembelajaran berbicara harus sering dilatih terus-menerus. Salah satunya dengan cara mahasiswa harus berani berbicara menyampaikan pendapatnya di depan teman-temannya. Berbicara merupakan salah satu bagian dari komunikasi, dimana berbicara merupakan bentuk kegiatan komunikasi lisan (Alibakhshi dan Padiz, 2011: 141). Menurut Bygate (2000: 11), komunikasi adalah serangkaian perbuatan komunikasi yang dipergunakan secara sistematis untuk menyelesaikan atau mencapai maksud-maksud tertentu. Dengan demikian, mahasiswa dituntut mampu berbicara/ menyampaikan sebuah informasi/materi agar dapat dipahami orang lain. Pembelajaran berbicara yang dilakukan dengan kegiatan komunikatif dinilai lebih menyenangkan daripada yang tidak komunikatif (Green, 1993: 2; Hughes, 2003: 14). Secara umum hasil penelitian ini menunjukkan bahwa penggunaan metode kooperatif tipe Jigsaw mampu meningkatkan kualitas proses dan hasil pembelajaran keterampilan berbicara (Thuy, 2005; Tran, 2014; Kaur, 2017).

\section{SIMPULAN}

Simpulan penelitian ini menunjukkan bahwa penerapan metode kooperatif tipe Jigsaw dapat meningkatkan keaktifan mahasiswa, proses dan hasil pembelajaran keterampilan berbicara pada mahasiswa tingkat I-B (gasal) Prodi Pendidikan Bahasa dan Sastra Indonesia IKIP PGRI Bojonegoro Tahun Akademik 2018/2019.

\section{DAFTAR PUSTAKA}

Alibakhshi dan Padiz. 2011. "The Effect of Teaching Strategic Competence on Speaking Performance of ELS Learners". Journal of Langguage Teaching and Research. Vol. 2 (4) pp. 941-947. 
Attle, S., \& Baker, B. 2007. Cooperative learning a Comparative environment: Classroom applications. International Journal and Learning in Higher Education. Vol. 19 No. 1, pp.77-83.

Bahrani, Tahir dan Rahmatollah Soltani. 2008. "How to Teach Speaking Skill?". ELT Journaleltj Oxfordjournals. Org, Vol 62, Iss 2, Pp 131-138.

Bygate, Martin. 2000. Speaking. Oxford: Oxford University Press.

Darmuki, A., Andayani, Joko Nurkamto, Kundharu Saddhono. 2017. Evaluating Information-Processing-Based Learning Cooperative Model on Speaking Skill Course. Journal of Language Teaching and Reasearch. 8(1), 44-51.

Darmuki, A., Andayani, Joko Nurkamto, Kundharu Saddhono. 2017. Cooperative, Synectics, and CTL Learning. Proceeding International Conference on Intellectuals'Global Responsibility (ASSEHR). Vol. 125, 75-79.

Darmuki, A., Andayani, Joko Nurkamto, Kundharu Saddhono. 2018. The Development and Evaluation of Speaking Learning Model by Cooperative Approach. International Journal of Instruction. 11(2), 115-128.

Gilles, Robyn dan Boyle, Michael. 2010. "Teacher reflections on Cooperative Learning: Issues of Implementation". Teaching and Teacher Education. Vol. 26 pp. 933-940.

Hughes, Arthur. 2003. Testing for Language Teacher. Second Edition. Cambridge University Press.

Joice, B., MarshaWeil, dan Emily Calhoun. 2011. Model of Teaching. Eight Edition. USA: Pearson Education, Inc.

Kayi, H. 2006. Teaching Speaking Activities to Promote Speaking in a Second Language. The Internet TESL Journal. 7 (11).

Klimoviene, Giedre. 2006. "Using Cooperative Learning to Develop Language Competence and Social Skill”. Studies About Languages. Vol 8 Pp 77-83.

Lavasani, M. G., Afzali, L., \& Afzali, F. 2011. Cooperative Learning and Social Skills. Cypriot Journal of Educational Science. Vol.4.No 10. Pp. 186-193. 
Liao, Guoqiang. 2009. "Educational Technology \& Society, Improvement of Speking Ability Through Interralated Skills".Journal of Langguage Teaching and Research. Vol. 1 (3) pp 643.658

Lie, Anita. 2008. Kooperatif Learning. Jakarta: PT Gramedia.

Lie, Anita. 2005. Cooprative Learning: Mempraktikkan Cooperative Learning di Ruang-Ruang Kelas. Jakarta: Grasindo.

Lourdunathan, Josephine dan Sujatha Menon. 2011. "Developing Speaking Skill Through Interaction". The English Teacher Journal.University Teknologi MARA. Vol. 34. Pp 1-18.

Morgan, Bobette. 2012. "Teaching Cooperative Learning with Childrens Literature". National Forum of Teacher Educational Journal. Vol. 22(3) pp. 234-246.

Murdoch, K. \& Wilson, J. 2004. How to Succeed with Cooperative Learning. Australia: Curriculum Corporation.

Ning, H. 2010. Adapting Cooperative in Tertiary ELT. ELT Journal. 65(1). 60-70. Nurgiyantoro, Burhan. 2010. Penilaian Pembelajaran Bahasa Berbasis Kompetensi. Yogyakarta: BPFE.

Pan, Lili. 2010. "International Students in English-Speaking Universities: A Study of Public Speaking in Korean Educational Chinese Students". Journal of Langguage Teaching and Research. Vol. 1 (6) pp 922-925.

Pandey dan Kishore. 2010. Effect of Cooperative Learning on Cognitive Achievemet in Science. Journal of Science and Mathematics Education in Asia.Vol. 26. No. 252.

Pandya Shefali. 2010. Interactive Effect of Cooperative Learning Model and Learning Goals of Students on Academic Achievement of Student in Mathematics. Mevlana International Journal of Education. Vol. 1(2) pp. 2734.

Parveen dan Batool. 2012. Effect of Cooperative Learning on Achievement of Students in General Science at Secondary Level. International Education Studies. Vol. 5, No. 2. 
Slavin, Robert E. 2009. Cooperative Learning Teori, Riset dan Praktik. Bandung: Nusa Media.

Susan, R. 2009. The Jigsaw Classroom. Connecting Education and Careers. 84(4) pp. 8-19.

Suwantarathip, O., \& Woolfolk, S. 2010. The Impact of Cooperative Learning on Anxiety and Proficiency in an EFL Class. Journal of College Teaching and Learning. 7(11). 51-58.

Syaodih, Nana. 2007. Pengembangan Model Pembelajaran Kooperatif untuk Meningkatkan Keterampilan Sosial. Jurnal Pendidikan. Vol. 39. No. 2. Pp. 129-140.

Talebi, Ferina. 2012. "The Impact of Cooperative Learning on Oral Proficiency". Mediterranean Journal of Social Sciences. Vol 3. Iss 3. Pp.75-79.

Thornbury, Scott. 2001. How to Teach Speaking. Tanpa Kota: Longman.

Thuy, Le Thi Bich. 2005. "An Action Research on the Application of cooperative Learning to Teaching Speaking”. TESOL. Journal, Vol 1, pp. 332-349.

Thuy, Nguyen Thi Thu. 2012. Effectiveness of Jigsaw, Think Pair Share and Numbered Head Together on Student Oral Participation in Speaking Lessons. Mediterranean Journal of Social Sciences. Vol 3. Iss 3. Pp. 120-132.

Trianto. 2007. Model-Model Pembelajaran Inovativ Berorientasi Konstruktivistik. Jakarta: Prestasi Pustaka.

Wood, Denise dan Chen, Kuan-Chou. 2010. Evaluating Tenchniques for Cooperative Learning. International Journal of Management dan Information Systems-First Quarter. Vol.14.No.1.

Young, Showing and Shyh-Jane Li. 2010. An Action Research on System Dynamics Course Through Cooperative Learning. Action Research. Vol. 7. Pp. 170-184. 